\title{
INSIGHTS
}

\section{Honoring Gus: lessons learned about creating memories in the NICU}

\author{
Alison Falck ${ }^{1}$, Brenda Hussey-Gardner ${ }^{1}$, Pamela Purdy ${ }^{2}$ and Nicole Pray ${ }^{2}$ \\ Pediatric Research (2020) 88:512-513; https://doi.org/10.1038/s41390-019-0638-7
}

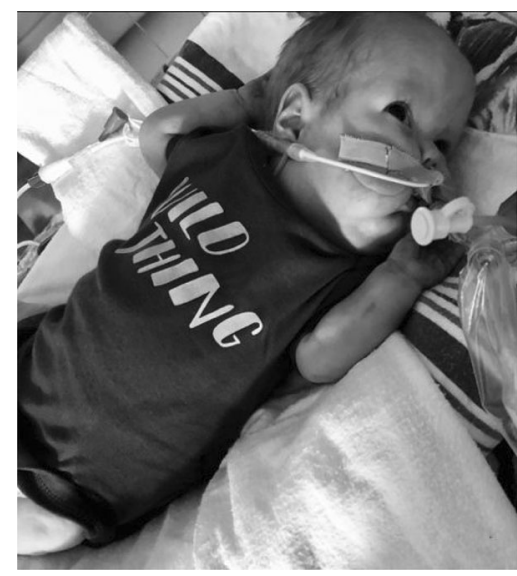

Gus was born at home, precipitously and unexpectedly, at 26 weeks' gestation. He was transferred to our Level IV Neonatal Intensive Care Unit (NICU) from a local community hospital after his lungs continued to fail at 2 months of life. His given name was Langdon, but he received the nickname Gus from his parents, because his protuberant abdomen reminded them of Cinderella's friend, the mouse named Gus-Gus. It stuck, and to all of us he was known and lovingly referred to as Gus.

Gus lived for 5 months in our NICU. During his short life, there were far more difficult times than periods of stability. He was never able to be extubated from the ventilator and eventually required a central line, tracheostomy, and gastrostomy tube, among other surgeries. His problem list was long and complicated; a stressful scenario endured by many NICU families. Fortunately, Gus was blessed with a wonderful family. His parents are bright, warm, and instantly likeable people. They were a constant at the bedside, advocating for Gus. They remained realistic but hopeful throughout their NICU stay. During our frequent goals of care meetings, we developed a trusting, reciprocal, and respectful rapport. Laughter and tears were equally shared. His parents asked us to guide them, knowing their values and perspectives, as to when it was time to shift our focus to palliative care and planning for end of life.

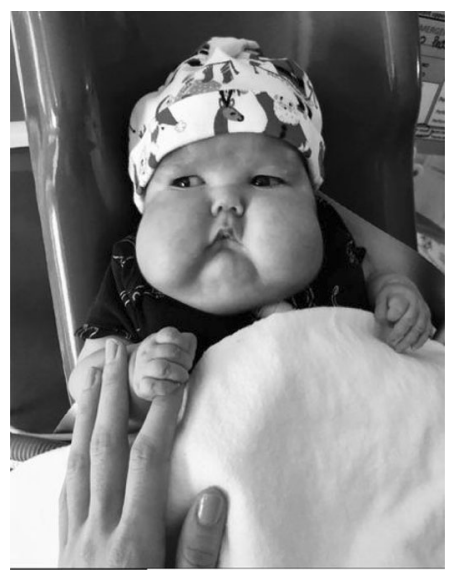

While Gus was not actively dying, he was not getting better. He continued to grow and showed some developmental progress. However, as he grew, his lungs continued to fail. He required high $\mathrm{FiO}_{2}$ and very high settings on the ventilator. He developed pulmonary hypertension and needed escalating sedation and pain medications to support his fragile condition. While he responded to courses of steroids, he began to require more frequent "rescue" dosing and eventually would not tolerate being weaned. We worried about the long-term impact of these steroids on his premature organ systems, especially on his brain, the effects already apparent outwardly in his Cushingoid appearance.

As time passed, we became increasingly concerned about his ability to survive the NICU, and for his neurodevelopmental prognosis, should he survive. This was a gray area for his medical team; we questioned ourselves and each other regularly. Would he survive to discharge and go home? How long would his lungs support life outside the hospital? Would he be ventilator dependent for months, years, the rest of his life? Would he make neurodevelopmental progress? What impact would his long-term illness have on his family? There were times when Gus would make eye contact, track with his eyes, and seem to connect. And then, there were increasingly frequent times when he would struggle to breathe or show signs of pain. Eventually, our family meetings shifted from strategizing about goals of care to improve

${ }^{1}$ University of Maryland School of Medicine, Baltimore, MD, USA and ${ }^{2}$ University of Maryland Medical Center, Baltimore, MD, USA

Correspondence: Alison Falck (afalck@som.umaryland.edu)

Received: 16 October 2019 Accepted: 16 October 2019

Published online: 9 November 2019 
his medical status to a focus on family values and the meaning of quality of life. Continuity, teamwork, and trust were irreplaceable and allowed for open and honest communication around these concepts. When it became clear that Gus was suffering more than he was making progress, we shared these concerns with his parents. We decided together to focus on memory making, and the best ways to honor Gus as we planned the end of his life.

Our first memory-making experience centered around planning a 6-month birthday party. The complexity of Gus' illness and his labile status often left his caregivers exhausted and drained. This celebration allowed his primary nurses to shift their intense medical focus for a short period of time to the simple task of planning a birthday party; a diversion from the seriousness of his illness and a fun celebration for his family. The family was grateful for the effort put forth by our nurses, and truly enjoyed celebrating this milestone.

Subsequently, we helped the family prioritize the memories that they wanted to create with their son, as they prepared for end of life. Obtaining a recording of Gus' heartbeat was very meaningful to his parents. His heartbeat, recorded with a handheld Doppler, was given to his parents on a USB flash drive. Gus' parents regularly would sit at his bedside and read the Harry Potter novels to him, "the boy who lived." Thus we purchased a Harry Potter flash drive, a Christmas present from Santa to Gus. A journal for staff, relatives, and friends to write notes to Gus also resonated with his mother. The journal, chosen by his mother, was quickly filled with heartfelt messages and stories, taken home after his death and saved by the family to read when they were ready.

Family time was planned with Gus, his parents, and 1-year-old brother, nicknamed Squish. The family made stepping stones for their garden with hand and foot prints of both of their children. They then shared story time on a floor mat in his room; this was the only time that Gus' mother held both of her boys at the same time. Other craft projects included creating Christmas ornaments and picture frames with Gus' finger, hand, and footprints.

Capturing Gus through photography was also important to the family. In addition to the many pictures that the family took, we arranged a photo session to recreate photos, taken of Squish when he was a baby, with Gus. Another one of his parent's hopes was for Gus to go outside. It was winter in Baltimore City when we began discussing this outing. Gus was critically ill at that time, on high ventilator settings delivered via a tracheostomy and with a central line continuously infusing fluids and sedation and pain medications required for him to remain stable. An option was suggested to instead visit the hospital healing garden, a peaceful setting outside the NICU with a glass ceiling and garden. The date was set at a time when extended family could also be present. The pictures taken in the healing garden captured such joy on his parents' faces as they held their baby surrounded by grandparents and other loved ones.

The parents expressed interest in organ donation, a selfless act that would honor their son's life while saving another. As we planned the final hours of his life, Gus' mother voiced a desire to cuddle in bed with her now 7-month-old baby. On the day prior to the withdrawal, an adult-sized hospital bed was brought to the NICU and his parents climbed in, staying with him through the night.

As Gus was a heart valve donor, a "walk of honor" was held on the day of planned withdrawal, to honor his life and this donation of life. With such a prolonged NICU stay, Gus and his family were known to many providers throughout the hospital. At the designated time and prior to the withdrawal, his parents and primary medical team walked around the NICU, with Gus attached to his equipment and in his crib. Interdisciplinary providers from all over the hospital silently filled the halls of our 37,000 square foot NICU; shoulder to shoulder holding tea lights. The emotions during this walk are indescribable. As we reached the final turn back to the room, Gus' father stopped, turned around, and expressed his gratitude to a hallway filled with love, respect, and empathy. Gus' death was peaceful, he was held by his parents, cuddling in bed, as we withdrew the ventilator.

In the NICU, we have the privilege of being a part of the journey of numerous families; so many stories that they start to fade and blur as time passes. But some people teach you, touch you, and change you forever. Gus touched this world not only through his organ donation but also through the lessons he and his family taught us. They reminded us that, in addition to the provision of medical care, equally important is the journey we walk with families to create precious, lifelong memories.

\section{ADDITIONAL INFORMATION}

Informed consent: Informed consent was obtained from Alex Landis and Tyler Jones (parents of Gus) for image publication. 